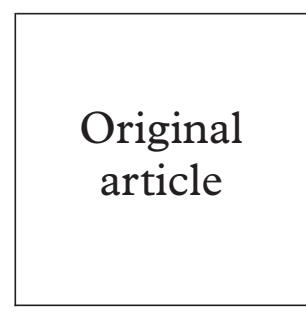

\title{
Report of sexually transmitted diseases by HIV infected men during follow up: time to target the HIV infected?
}

\author{
R N Machekano, M T Bassett, P S Zhou, M T Mbizvo, A S Latif, D A Katzenstein
}

Objectives: To compare the rate of self reported sexually transmitted diseases (STDs) among HIV infected men with men who remained HIV negative during follow up of a Harare male factory cohort.

Methods: Male factory workers were offered enrolment and behavioural data were collected at entry then every 6 months, along with HIV testing. Self report of STDs was used to calculate incidence per 100 person years. Cox proportional hazards models examined independent risk factors for STDs, with hazard ratios (HRs).

Results: At entry $20 \%$ of men were HIV infected and $11 \%$ reported STDs in the previous year. A total of $2777(82 \%)$ of 3383 men enrolled were followed at least once. Compared with men who remained HIV negative, seroconverters had the highest incidence of STDs (16.8 per 100 person years; $\mathrm{IRR}=3.3,95 \% \mathrm{CI}=2.5-4.3)$; men enrolled HIV positive also reported higher STD incidence (14.5 per 100 person years, IRR=2.8; 95\%CI 2.3-5.5). Among HIV positive men, the only independent risk factor for report of urethral discharge was history of multiple partners $(\mathrm{HR}=10,95 \% \mathrm{CI} 1.4-73.2)$.

Conclusion: HIV positive men reported threefold higher incidence of STDs than HIV negative men, many related to high risk sexual behaviour.

(Sex Transm Inf 2000;76:188-192)

Keywords: AIDS; sexually transmitted diseases; HIV; Zimbabwe

\section{Introduction}

In Zimbabwe, the HIV/AIDS epidemic is among the most severe in the world and sexually transmitted diseases (STDs) are common. ${ }^{1-3}$ Prevention efforts have emphasised reduction in HIV risk behaviour, regardless of HIV infection status, as a key to containing the epidemic. Encouraging the identification of HIV infected individuals to promote behaviour change and reduce the spread of HIV has not been a strategy of Zimbabwe's national AIDS coordination programme. By targeting behaviour, rather than individuals, it was hoped to avoid stigmatising vulnerable risk groups (such as prostitutes) and alert the population to the fact that behavioural risk was not confined to any particular social group. This policy perspective and the cost of widespread voluntary HIV screening have meant that few HIV positive Zimbabweans are aware of their serostatus. Indeed, Zimbabwe's ongoing economic crisis has limited even the availability of male condoms to an estimated 15 condoms per adult per year. ${ }^{3}$ In Harare, with an adult population of one million, about 65000 HIV tests are performed annually by the national public health laboratory and national blood transfusion service, the only sources of testing outside the private sector (personal communication). Testing is mainly for diagnostic purposes among symptomatic individuals or to screen the blood supply (which accounts for two thirds of tests). HIV counselling and testing of the healthy population, aside from blood donation, has only recently been promoted at a small number of sites.
Although a focus on individuals who are $\mathrm{HIV}$ infected poses a number of logistic, policy, and ethical difficulties, ${ }^{4}$ the behaviour of this group is clearly important to the pattern of the epidemic. ${ }^{5}$ In addition, the intersection of the HIV epidemic with other bacteriological and viral STDs also common in Zimbabwe probably enhances HIV transmission. ${ }^{6-9}$

We utilised data from a longitudinal study of Harare male factory workers to compare the patterns of self reported STDs according to the men's HIV infection status at enrolment and during follow up. This cohort was at high risk for HIV infection. At enrolment, $43 \%$ of men reported multiple partners in the past year, $19 \%$ had paid for sex, $55 \%$ had never used condoms, and $20 \%$ were HIV positive. ${ }^{10}$ HIV incidence was 3 per 100 person years. ${ }^{11}$

\section{Methods}

STUDY SUBJECTS, RECRUITMENT, AND FOLLOW UP Factory workers were recruited to a longitudinal study of STD/HIV at 40 factories in Harare, Zimbabwe. Workers employed at the factories volunteered to be tested twice a year for HIV infection, as previously described. ${ }^{10}{ }^{11}$ Incentives for participation included free counselling and HIV testing. Trained nurse counsellors provided group pretest counselling at the workplace on the day before study recruitment followed by a brief individual discussion at the time of recruitment. Post-test counselling was at the study clinic and typically comprised 30 minutes of interactive counselling aimed at individual risk reduction. After signed informed consent, a questionnaire collected 


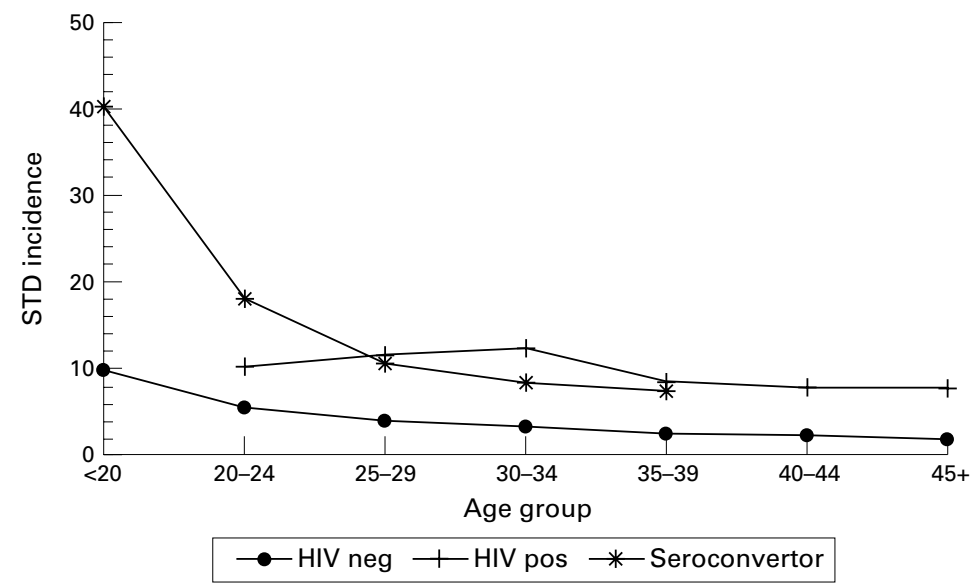

Figure 1 Self reported STD incidence by age group and HIV serostatus.

information on sociodemographic status, sexual behaviour, condom use, and STDs. Volunteers were seen every 6 months at repeat visits to the factories. Follow up questionnaires replicated information collected at enrolment and identified reported risk behaviour, experience of STDs, and the treatment of these infections during the interval since the last visit. All enrolled men were offered condoms, an appointment for post-test counselling at the project clinic, and were encouraged to seek treatment for STDs, which was available free of charge at the study clinic. The study protocol was reviewed and monitored by committees for human research in Zimbabwe and the United States.

\section{HIV SEROSTATUS}

Blood samples were screened at enrolment and at each follow up visit for HIV specific antibodies using a third generation ELISA test, the Abbott HIV-1/HIV-2 (Abbott Park, IL, USA). Subjects were considered HIV antibody negative based on a single negative test. Samples that were either reactive or indeterminate on the Abbott test were retested using a different third generation ELISA, the Enzygnost Anti-HIV 1/2 Plus (Behring, Marburg, Germany). Subjects were classified as HIV antibody positive if both ELISA assays were positive. Indeterminate or conflicting results between the two recombinant ELISA tests were resolved variously by western blot, the HIV Blot 2.2 (Diagnostic Biotechnology,
Singapore), HIV cultures, or polymerase chain reaction (PCR) amplification of specific gag gene DNA. We classified enrolled men according to their HIV serostatus at enrolment and during subsequent follow up. Men who had an initial negative test result followed by a positive test result were classified as seroconverters. Men who were negative at enrolment and tested negative on subsequent follow up visits were classified as persistently negative.

INTERVIEW DATA

On interview, reported STD was classified by its symptomatic presentation (urethral discharge, genital ulcer, genital warts, or other). Data were collected on condom use, number of sexual partners, prostitute contact, and beer hall visits.

\section{STATISTICAL METHODS}

STD incidence was estimated as the total number of individuals reporting an STD divided by the total person time of follow up, expressed as per 100 person years, summarised in the equation below:

(Total No of subjects reporting a STD $\times$ 100)/total person years under observation

For calculation of STD incidence, the total person years under observation were calculated for each subject as the date of enrolment to the last follow up date. Seroconversion was defined as an initial negative HIV test followed by a subsequent positive test. The date of seroconversion was estimated as the midpoint between the date of the last negative test and the date of the first HIV diagnosis. This date was also used to calculate STD incidence before and after seroconversion. We used the incidence rate ratio (IRR) to measure association of STDs, HIV serostatus, and age. The Cox proportional hazards model was used to establish independent risk factors for acquiring a STD during follow up by calculating the hazard ratio (HR). Analyses were carried out using STATA 5.0 (Stata Corporation, College Station, TX, USA).

\section{Results}

Between March 1993 and July 1997, 3383 men (34\% of the total workforce) volunteered for the study. Of these, 2777 (82\%) were followed at least once. At enrolment, HIV prevalence

Table 1 Self reported STD incidence by HIV serostatus

\begin{tabular}{|c|c|c|c|c|c|}
\hline HIV serostatus & No & $\begin{array}{l}\text { No of } S T D \\
\text { episodes reported } \\
\text { in follow up }\end{array}$ & $\begin{array}{l}\text { Incidence/100 PY } \\
(95 \% \mathrm{CI})\end{array}$ & $\begin{array}{l}\text { Incidence rate ratio } \\
(I R R)(95 \% \mathrm{CI})\end{array}$ & $p$ Value \\
\hline \multicolumn{6}{|l|}{ All STDs: } \\
\hline HIV positive at enrolment & 666 & 158 & $14.5(12.3-16.9)$ & $2.8(2.3-3.5)$ & $<0.001$ \\
\hline Seroconverters & 147 & 67 & $16.8(13.0-21.4)$ & $3.3(2.5-4.3)$ & $<0.001$ \\
\hline Non-seroconverters & 2476 & 257 & $5.1(4.5-5.7)$ & Referent & - \\
\hline Total & 3289 & 482 & $7.4(6.7-8.1)$ & & \\
\hline \multicolumn{6}{|l|}{ Genital ulcers: } \\
\hline HIV positive at enrolment & 666 & 75 & $6.9(5.4-8.6)$ & $4.1(3.0-5.7)$ & $<0.001$ \\
\hline Seroconverters & 147 & 34 & $8.5(5.9-11.9)$ & $5.1(3.3-7.7)$ & $<0.001$ \\
\hline Non-seroconverters & 2476 & 84 & $1.7(1.3-2.1)$ & Referent & - \\
\hline Total & 3289 & 193 & $2.9(2.5-3.4)$ & & \\
\hline \multicolumn{6}{|l|}{ Urethral discharge: } \\
\hline HIV positive at enrolment & 666 & 39 & $3.6(2.5-4.9)$ & $2.2(1.5-3.4)$ & $<0.001$ \\
\hline Seroconverters & 147 & 18 & $4.5(2.7-7.1)$ & $2.8(1.6-4.8)$ & $<0.001$ \\
\hline Non-seroconverters & 2476 & 80 & $1.6(1.2-2.0)$ & Referent & - \\
\hline Total & 3289 & 137 & $2.1(1.8-2.5)$ & & \\
\hline
\end{tabular}


Table 2 Behavioural risk factors for STD infection during follow up among HIV negative individuals $(n=1784)$

\begin{tabular}{|c|c|c|c|c|c|}
\hline Behavioural factor & $\begin{array}{l}\text { Men reporting an } \\
\text { STD during follow up } \\
\text { No (\%) }\end{array}$ & $\begin{array}{l}\text { Total follow up time } \\
\text { (years) }\end{array}$ & $\begin{array}{l}\text { STD incidence } 100 \\
\text { person years }(95 \% \mathrm{CI})\end{array}$ & $\begin{array}{l}\text { Adjusted hazard } \\
\text { ratio }(95 \% \text { CI) }\end{array}$ & p Value \\
\hline \multicolumn{6}{|l|}{ Own a home: } \\
\hline Yes & $19(4.6)$ & 1069 & $1.8(1.1-2.8)$ & $0.4(0.2-0.6)$ & \multirow[t]{2}{*}{0.001} \\
\hline No & $175(10.8)$ & 3986 & $4.4(3.8-5.1)$ & - & \\
\hline \multicolumn{6}{|l|}{ Married: } \\
\hline Yes & $87(11.8)$ & 1683 & $5.2(4.1-6.4)$ & * & \multirow[t]{2}{*}{$\star$} \\
\hline No & $107(8.3)$ & 3372 & $3.2(2.6-3.8)$ & & \\
\hline \multicolumn{6}{|c|}{ Used a condom during follow up: } \\
\hline Yes & $154(13.6)$ & 3022 & $5.1(4.3-6.0)$ & $1.6(1.1-2.5)$ & \multirow[t]{2}{*}{0.022} \\
\hline No & $40(4.5)$ & 2033 & $2.0(1.4-2.7)$ & - & \\
\hline \multicolumn{6}{|c|}{ Reported multiple partners during follow up: } \\
\hline Yes & $150(15.0)$ & 2614 & $5.7(4.8-6.7)$ & $2.0(1.3-3.0)$ & \multirow[t]{2}{*}{0.001} \\
\hline No & $44(4.3)$ & 2441 & $1.8(1.3-2.4)$ & - & \\
\hline \multicolumn{6}{|c|}{ Reported paying for sex during follow up: } \\
\hline Yes & $58(16.2)$ & 880 & $6.6(5.0-8.5)$ & $1.4(1.0-2.0)$ & \multirow[t]{2}{*}{0.041} \\
\hline No & $103(7.2)$ & 3486 & $3.0(2.4-3.6)$ & - & \\
\hline \multicolumn{6}{|c|}{ Visited a beer hall during follow up: } \\
\hline Yes & $132(11.0)$ & 3152 & $4.2(3.5-5.0)$ & * & \multirow[t]{2}{*}{ * } \\
\hline No & $62(7.5)$ & 1903 & $3.2(2.5-4.2)$ & & \\
\hline
\end{tabular}

*Variables dropped in the multivariate analysis.

was $20 \%$ and $374(11 \%)$ men reported history of STD in the past year. Among men with STD, symptoms of genital ulcer were most common $(41 \%)$, followed by reported urethral discharge (32\%). Genital wart was reported by $6 \%$ of men. The category "other" comprised such syndromes as pubic lice, candida balanitis, rash in the genital area, and inguinal lymphadenopathy. Report of STD declined steadily with age in all men, regardless of HIV infection status, with the most rapid fall reported by persistently HIV negative men (see fig 1).

Table 1 summarises the overall incidence of self reported STDs by HIV serostatus during the study period. Compared with individuals who remained HIV negative throughout follow up, men who acquired HIV during the 4 year study period ("seroconverters") were the most likely to report STDs although STD rates did not differ statistically from men who were seropositive on enrolment. This increased risk was substantial, ranging from a threefold increased risk for report of urethritis to a fivefold increase for genital ulcer. Among seroconverters, report of STDs varied with changing HIV status. These men were twice as likely to report STDs after acquiring HIV (an incidence of 9.3 per 100 person years before compared with an incidence of 17.6 after seroconversion (IRR = 1.9; 95\% CI: $1.1-3.5, \mathrm{p}<0.001)$ ).

Among HIV negative individuals, not owning a home in the urban area, having multiple partners, paying for sex, and using a condom were significantly associated with reporting a STD during follow up (table 2). Married men also had a higher STD incidence compared with unmarried men $(\mathrm{IRR}=1.6,95 \%$ CI $1.2-$ $2.2, \mathrm{p}<0.001)$.

Among the HIV positive individuals, report of condom use in the last sexual encounter was the only significant behavioural risk factor associated with report of STD during follow up. Controlling for multiple partners, paying for sex, visiting a beer hall, and age, individuals who reported using condoms in their last sexual encounter were almost twice likely to report an STD during follow up compared with those who did not report condom use ( $\mathrm{HR}=1.7 ; 95 \%$ CI $1.0-2.7)$.

Because the natural history of genital ulcer is altered by HIV related immunosuppression, the recurrence of genital ulcer is more frequent in HIV positive individuals. Consequently, genital ulcer may not reliably reflect new STD exposure. For this reason, we examined separately risk factors for urethral discharge to better capture the experience of incident

Table 3 Behavioural risk factors for urethral discharge during follow up among HIV positive patients $(n=490)$

\begin{tabular}{|c|c|c|c|c|c|}
\hline Behavioural factor & $\begin{array}{l}\text { Men reporting urethral } \\
\text { discharge during follow } \\
\text { up No (\%) }\end{array}$ & $\begin{array}{l}\text { Total follow up } \\
\text { time (years) }\end{array}$ & $\begin{array}{l}S T D \text { incidence } 100 \\
\text { person years }(95 \% \mathrm{CI})\end{array}$ & $\begin{array}{l}\text { Adjusted hazard ratio } \\
(95 \% \text { CI) }\end{array}$ & $p$ Value \\
\hline \multicolumn{6}{|l|}{ Own a home: } \\
\hline Yes & $2(4.0)$ & 109 & $1.8(0.2-6.6)$ & \multirow[t]{2}{*}{$\star$} & \multirow{2}{*}{ * } \\
\hline No & $32(6.9)$ & 981 & $3.3(2.2-4.6)$ & & \\
\hline \multicolumn{6}{|l|}{ Married: } \\
\hline Yes & $6(4.5)$ & 278 & $2.2(0.8-4.7)$ & \multirow[t]{2}{*}{ * } & \multirow[t]{2}{*}{ * } \\
\hline No & $28(7.4)$ & 813 & $3.4(2.3-5.0)$ & & \\
\hline \multicolumn{6}{|c|}{ Used a condom during follow-up: } \\
\hline Yes & $31(8.7)$ & 830 & $3.7(2.5-5.3)$ & \multirow[t]{2}{*}{$\star$} & \multirow[t]{2}{*}{ * } \\
\hline No & $3(1.9)$ & 261 & $1.2(0.2-3.4)$ & & \\
\hline \multicolumn{6}{|c|}{ Reported multiple partners during follow up: } \\
\hline Yes & $33(9.2)$ & 805 & $4.1(2.8-5.8)$ & $10.0(1.4-73.2)$ & \multirow[t]{2}{*}{0.024} \\
\hline No & $1(0.6)$ & 285 & $0.4(0-1.9)$ & - & \\
\hline \multicolumn{6}{|c|}{ Reported paying for sex during follow up: } \\
\hline Yes & $19(10.4)$ & 401 & $1.7(2.8-7.4)$ & \multirow[t]{2}{*}{$\star$} & \multirow[t]{2}{*}{$\star$} \\
\hline No & $15(4.9)$ & 641 & $2.3(1.3-3.8)$ & & \\
\hline \multicolumn{6}{|c|}{ Visited a beer hall during follow up: } \\
\hline Yes & $30(7.5)$ & 873 & $3.4(2.3-4.9)$ & \multirow[t]{2}{*}{$\star$} & \multirow[t]{2}{*}{ * } \\
\hline No & $4(3.4)$ & 217 & $1.8(0.5-4.7)$ & & \\
\hline
\end{tabular}

*Variables dropped in the multivariate analysis. 
STDs. Among HIV positive men, reporting multiple partners was the only risk factor for urethral discharge during follow up (table 3 ).

\section{Discussion}

Using data from a Harare male cohort, we characterised the pattern of self reported STDs in a population with a high HIV prevalence. Follow up data made it possible to examine the STD experience reported by men according to their HIV status. Our findings suggest that men who are HIV infected continue to acquireand presumably transmit-other STDs at a much higher rate (from two to fivefold) than HIV negative men. While more frequent occurrence of a genital ulcer may represent recurrent genital herpes, rather than a newly acquired STD, urethral discharge was also twice as common in men who were HIV positive at enrolment or acquired HIV during follow up compared with persistently HIV negative men. Indeed, report of multiple partners was the only significant risk factor for urethral discharge among HIV positive men. In this study, condom use was not protective against STDs among either HIV positive or HIV negative men, perhaps because condoms were a proxy for risk behaviour and used inconsistently. HIV positive men were more likely to use a condom than HIV negative men. ${ }^{10}$ Our data are limited by the fact that all STD data are based on self report and lack clinical or microbiological confirmation. Subjects were all volunteers willing to have HIV testing and may not have been representative of the workforce generally.

It is perhaps not surprising that our data suggest that the risky behaviour which results in HIV acquisition continued after HIV infection. The implications of this observation for prevention, however, have been little discussed. Should there be prevention messages aimed especially at HIV positive individuals? Behaviour change among the infected population surely is necessary. Continued acquisition of STDs not only has an impact on the population prevalence of HIV, but may also affect the clinical course of the infected individual. There is evidence to suggest that avoidance of other STDs or reinfection with HIV is a healthy strategy for those living with HIV. ${ }^{12}$

How might we have intervened better among these men? Many men in our cohort did not know their HIV status, because they failed to seek their test results (which were available only at the study clinic and not at the workplace where testing was performed). Of the 3383 men enrolled in this study, 1903 (56\%) chose to receive their HIV test results. In another analysis, we noted that men who learned their HIV test result were less likely to seroconvert compared with men who did not learn the test result, although this was not statistically significant (IRR $=0.63$; 95\%CI 0.31-1.30, $\mathrm{p}=0.18) .{ }^{13}$ Among HIV positive men, no difference was found in STD occurrence subsequent to learning a test result. This finding may have been biased by the fact that visits to the study clinics for STD treatment often led to provision of HIV test results. ${ }^{13}$

There are now data from other developing country settings to suggest that voluntary counselling and testing may result in sustained behavioural change regardless of test result, especially with same day results now possible with rapid tests. ${ }^{14-16}$ Providing HIV counselling and testing in the setting of STD care would result in identification of men at high risk for HIV. Targeting patients with STDs for HIV testing would be more affordable than a general population approach.

More effective use of the clinical care setting to promote prevention might also help slow population spread of HIV. Data suggest that the curative encounters for a clinical STD often lack even rudimentary prevention advice. An assessment of STD services in Malawi showed that $20 \%$ of the clients were given condoms. ${ }^{17}$ A study in the United States suggested that not only condom advice, but explicit condom demonstrations were keys to condom adoption. ${ }^{18}$ As many men in the present study had never used a condom, more than simple advice will be needed. The outpatient setting, STD clinics, and TB clinics are greatly underutilised for the promotion HIV risk awareness, need for behaviour change, and condom use. ${ }^{19}$ Few clinicians even mention that a person with a bacterial STD is at risk for HIV, or that in HIV high prevalence areas, most TB patients are also HIV infected.

Finally, our data suggest the importance of promoting responsible behaviour in those who are HIV positive. Such intervention messages carry the risk of creating a victim blaming approach. ${ }^{4}$ In Zimbabwe, as elsewhere, individual sexual behaviour is not a simple matter of individual choice. Many structural factorssuch as growing poverty, absence of income earning opportunities for women, male migration, increasing military deployment-create the setting of individual risk. ${ }^{20}$ An acknowledgement of society's responsibility to reduce the "risky" situation that exits for too many must balance promotion of individual responsibility of the HIV positive population. Mobilisation of resources to improve access to counselling and testing might be a first step.

The authors thank the research nurses, Martha Jeche, Athanasia Mashingaidze, Caroline Maposhere, Mary Matshaka, and Verna Mzezewe, The assistance of the National Blood Transfusion Service is gratefully acknowledged. The useful comments made Service is gratefully acknowledged. The useful co
by three anonymous reviewers were appreciated.

Contributors: RNM contributed to the writing of the first and
fon thee anonymous reviewers were appreciated. Contributors: RNM contributed to the writing of the first and
second drafts and performed the data analysis; MTB contributed to the overall design of the study, data collection and analysis, and wrote the final paper; PSZ performed the initial data analysis in the first draft; MTM contributed to the study design, oversaw initial analysis and preparation of the first draft; ASL contributed to the overall study design and was consultant to the study clinic; DAK was responsible for overall scientific direction of the Zimbabwe AIDS Prevention Project.

1 Joint United Nations Programme on AIDS (UNAIDS). AIDS Epidemic Update, December 1998.

2 National AIDS Co-ordination Programme. HIV AIDS, STD and TB fact sheet. Monitoring and evaluation unit, mimeo. Ministry of Health and Child Welfare, November mimeo.

3 UNAIDS Epidemiological Fact Sheet on HIV/AIDS and sexually transmitted diseases: Zimbabwe, June 1998.

4 Marks G, Burris S, Peterman TA. Reducing sexual transmission of HIV from those who know they are infected. The need for personal and collective responsibility. AIDS 1999;13:297-306. 
5 Vernazza PL, Eron JJ, Fiscus SA, et al. Sexual transmission of HIV. Infectiousness and prevention. AIDS 1999:13:15566.

6 Plummer FA. Heterosexual transmission of human immunodeficiency virus type 1 (HIV): interactions of conventional sexually transmitted diseases, hormonal contraception and HIV-1. AIDS Res Hum Retroviruses 1998; 14(Supp1 1):S5-10.

7 Hitchcock P, Fransen L. Preventing HIV infection. Lessons from Mwanza and Rakai [comment]. Lancet 1999;353:513-5.

8 Grosskurth H, Mosha F, Todd J, et al. Impact of improved treatment of sexually transmitted diseases on HIV infection in rural Tanzania: randomised controlled trial. Lancet 1995;346:530-6.

9 Cohen MS, Hoffman IF, Royce RA, et al. Reduction of concentration of HIV-1 in semen after treatment of urethritis: implications for prevention of sexual transmission of HIV1. Lancet 1997;349:1868-73.

10 Bassett MT, McFarland W, Ray S, et al. Risk factors for HIV infection at enrolment in a male factory cohort in Harare, Zimbabwe. $\mathcal{F}$ Acquir Immune Defic Syndr Hum RetHarare, Zimbabwe. $\mathcal{F}$ A

11 Mbizvo MT, Machekano R, McFarland W, et al. HIV seroincidence and correlates of seroconversion in a cohort of male factory workers in Harare, Zimbabwe. AIDS 1996; 10:895-901

12 Anzala OA, Nagelkerke NJ, Bwayo JJ, et al. Rapid progression to disease in African sex workers with human immunodeficiency virus type 1 infection. F Infect Dis 1995; 171:686-9.
13 Machekano R, McFarland W, Mbizvo MT, et al. Impact of HIV counselling and testing on HIV seroconversion and reported STD among male factory workers in Harare, Zimbabwe. Cent African F Med 1998;44:98-102.

14 Coates $T$. The efficacy of counselling and testing in reducing HIV risk in developing countries. A three-country randomized controlled trial. Abstract No 16.5th Conf Retrovir Oppor Infect, 1-5 February 1998

15 Downing RG, Otten RA, Marum E, et al. Optimizing the delivery of counseling and testing services. The Uganda experience using rapid HIV antibody test algorithms. F Acquir Immune Defic Syndr Hum Retrovirol 1998;18: 384-8.

16 McKenna SL, Muyinda GK, Roth D, et al. Rapid HIV testing and counseling for voluntary testing centres in Africa. AIDS 1997;Suppl 1:S103-10.

17 Chilongozi DA, Daly C, Franco L, et al. Sexually transmitted diseases. A survey of case management in Malawi. Int $\mathcal{F}$ STD AIDS 1996;7:269-75.

18 Faxelin E, Tembo G, Ndulo J, et al. Individual counselling of patients with sexually transmitted diseases. A way to improve partner notification in the Zambian setting? Sex Trans Dis 1996;23:289-92.

19 Cohen DA, Dent C, MacKinnon D, et al. Condoms for men, not women. Results of brief promotion programs. Sex Transm Dis 1992;19:245-51.

20 Zwi AB, Cabral AJ. Identifying "high risk situations" for preventing AIDS. BMF 1991;303:1527-9. 